\title{
Temperature-induced regional and temporal growth differences in Baltic young-of-the-year sprat Sprattus sprattus
}

\author{
Hannes Baumann ${ }^{1, *}$, Tomas Gröhsler², Georgs Kornilovs ${ }^{3}$, Andrej Makarchouk ${ }^{3}$, \\ Valerie Feldmann ${ }^{4}$, Axel Temming ${ }^{1}$ \\ ${ }^{1}$ Institute of Hydrobiology and Fisheries Science, Olbersweg 24, 22767 Hamburg, Germany \\ ${ }^{2}$ Institute for Baltic Sea Fisheries Rostock (IOR), An der Jaegerbaek 2,18069 Rostock, Germany \\ ${ }^{3}$ Latvian Fish Resources Agency, Daugavgrivas Street 8, Riga 1007, Latvia \\ ${ }^{4}$ Atlantic Research Institute of Marine Fisheries and Oceanography (AtlantNIRO), 5, Dmitry Donskoy Street, \\ 236000 Kaliningrad, Russia
}

\begin{abstract}
We examined spatial and temporal differences in growth patterns of young-of-the-year (YoY) sprat Sprattus sprattus synchronously sampled in October 2002 from 4 different regions of the Baltic Sea (western, central, eastern, northeastern Baltic). The microstructure of the sagittal otoliths of 427 individuals from 64 sampling sites were analysed to determine the day of first feeding (DFF) and the growth history of YoY survivors. DFF distributions differed markedly between Baltic areas, with a shift to later mean DFFs and narrower distributions from west to northeast. This was consistent with the shift in mean seasonal spawning effort of Baltic sprat, derived from long-term observations (1973 to 2002) of sprat egg abundance in these areas. Otolith growth trajectories (i.e. increment width-at-age) had a characteristic shape related to sampling area and, more importantly, to the time of the year at which the individual started feeding (DFF). During the larval stage, individuals from the northeastern area and those born later in the year had higher growth rates than their earlier born conspecifics, while the pattern was reversed during the juvenile stage. Weekly means of satellitebased sea-surface temperature were used to approximate the potential temperature history of YoY survivors, which significantly influenced the shape of the otolith growth trajectory. We conclude that different DFFs and therefore different temperature histories were primarily responsible for the largescale spatial growth variability between newly recruited Baltic YoY sprat in 2002.
\end{abstract}

KEY WORDS: Young-of-the-year sprat $\cdot$ Otolith microstructure analysis $\cdot$ Satellite data $\cdot$ Sea-surface temperature $\cdot$ Growth patterns $\cdot$ Day of first feeding $\cdot$ Egg abundance

\section{INTRODUCTION}

The sprat Sprattus sprattus is a small, pelagic, zooplanktivorous fish that occurs in most marine waters around Europe. In the Baltic Sea, which comprises the northern limit of its geographical distribution (Muus \& Nielsen 1999), sprat have become the most abundant commercially exploited fish species (ICES 2005a; see also www.ices.dk). Sprat are also of key dual importance to the Baltic ecosystem, both as a predator on the zooplankton community (Möllmann \& Köster 1999,
Köster \& Möllmann 2000, Kornilovs et al. 2001) and as a major prey species for Baltic cod, marine birds or mammals (Bagge et al. 1994). Baltic sprat stock abundance and recruitment success have shown large decadal trends, generally ascribed to a regime shift from a cod- to a clupeid-dominated ecosystem (Kornilovs et al. 2001, Köster et al. 2003), whereas the high inter-annual fluctuations in sprat recruitment success remain insufficiently understood (Baumann et al. in press). Prior investigations have confirmed that recruitment strength is mainly determined by differential survival patterns 
throughout the larval and early juvenile stages of sprat (Köster et al. 2003). Because survival in the field is often coupled with growth (Houde 1989), a better understanding of the processes that influence growth patterns in larval and juvenile Baltic sprat is desirable. However, an inherent limitation of growth studies on larvae and early juveniles is that 'average' patterns do not reflect the small fraction of individuals that will eventually emerge as survivors of these stages (Sharp 1987). It is thus meaningful to obtain samples from successful sprat recruits and investigate their growth histories, which can later be compared to individuals sampled earlier from the population.

Growth histories of sprat survivors are best inferred from otolith microstructure analysis of newly recruited, young-of-the-year (YoY) or 0-group sprat because, until their first winter, sprat are known to form readily discernible, daily increments that correspond in width to daily somatic growth rates and allow a direct backcalculation until the day of first feeding (DFF) (Baumann et al. in press). In sprat, DFFs comprise the best available proxy for hatch date, because regular increment formation during the yolk-sac stage is considered doubtful (Ré \& Gonçalves 1993).

Baltic sprat spawn over an extended period from March to August (Grimm \& Herra 1984) and within all major basins, from the Kiel Bight in the western Baltic to the Gulf of Finland in the northeast (Sjöblom \& Parmanne 1976, Grauman \& Krenkel 1986). Because the Baltic Sea is a very heterogeneous water body (MacKenzie et al. 2002), sprat larvae are likely to experience considerable spatial and temporal differences in environmental conditions, depending on DFFs and the region of origin (Nissling et al. 2003, Voss et al. 2006). In turn, this may lead to spatially and temporally different growth patterns in sprat survivors, and may also affect the timing and the length of the 'window of survival', i.e. the period when the majority of recruits is produced.

Field studies that attempt to explain variable growth patterns across large spatial scales (e.g. the Baltic Sea) are challenged by the necessity to cover large sampling areas in relatively short periods in order not to confound temporal with spatial variability. Such requirements are best met if multiple research cruises are conducted in parallel. Furthermore, potential differences in growth histories can only be attributed to differences in the environmental conditions experienced, if appropriate proxies for the environmental past of the studied individuals can be derived. Of the 2 major external factors influencing larval and juvenile fish growth, i.e. food availability and temperature (Heath 1992), the latter is generally less affected by small-scale variability (i.e. patchiness) and may thus be approximated more readily over the necessary spatial (here the Baltic Sea) and temporal (larval to juvenile stages) scales.
To derive temperature histories of field-caught fish larvae or juveniles, indirect methods such as hydrodynamic circulation models in conjunction with Lagrangian particle simulations have previously been applied (e.g. Hinrichsen et al. 2002, Baumann et al. 2003). Such approaches depend on the reliability of complex flow field estimates and, most importantly, on the inherent assumption that individuals would follow (or be randomly distributed around) the same backcalculated transport patterns as passively drifting particles. This is not justified in Baltic YoY sprat, which in autumn have already joined adult schools.

Alternatively, appropriate temperature proxies may be derived from satellite-based observations of seasurface temperature (SST) (e.g. Fowler \& Jennings 2003), since feeding sprat larvae are known to predominantly occur in surface waters (Voss et al. 2006). Despite the relatively coarse spatial and temporal resolution and unaccounted for larval/juvenile advection, satellite-based SSTs are in many ways advantageous over direct temperature measurements or modelling approaches. For example, long-term SST databases are often well established and readily accessed, and they provide spatially and temporally regular measurements for any desired areal coverage.

Here we used satellite-based SST data to approximate the temperature histories of YoY sprat caught in October 2002 within 4 large regions of the Baltic Sea (see Fig. 1). YoY growth histories were inferred from otolith microstructure analysis and tested for systematic differences between Baltic areas and among survivors born at different times in the year 2002. Our main goals were to describe the large-scale spatial variability in YoY morphology and to attempt to explain this by potential differences in growth arising from differences in temperatures experienced during the larval and juvenile stages.

\section{MATERIALS AND METHODS}

Field sampling. YoY sprat were sampled in October 2002 during the Baltic International Acoustic Survey (BIAS), conducted annually to yield abundance estimates for pelagic fish stocks. The survey consisted of 4 nearly parallel research cruises, which covered all regions of major sprat stock abundance in the Baltic Sea (Fig. 1, Table 1). The 4 ships deployed different pelagic fishing gears, with horizontal and vertical mouth openings of 21 to $90 \mathrm{~m}$ and 9 to $28 \mathrm{~m}$, respectively (ICES 2005b). In order to retain small pelagic fishes, the stretched mesh size in the cod end ranged from 12 to $20 \mathrm{~mm}\left(L_{50}=25\right.$ to $40 \mathrm{~mm}$ total length, where $L_{50}$ is the estimated length at which a fish has a $50 \%$ chance of being caught by the trawl: ICES 2005b), 


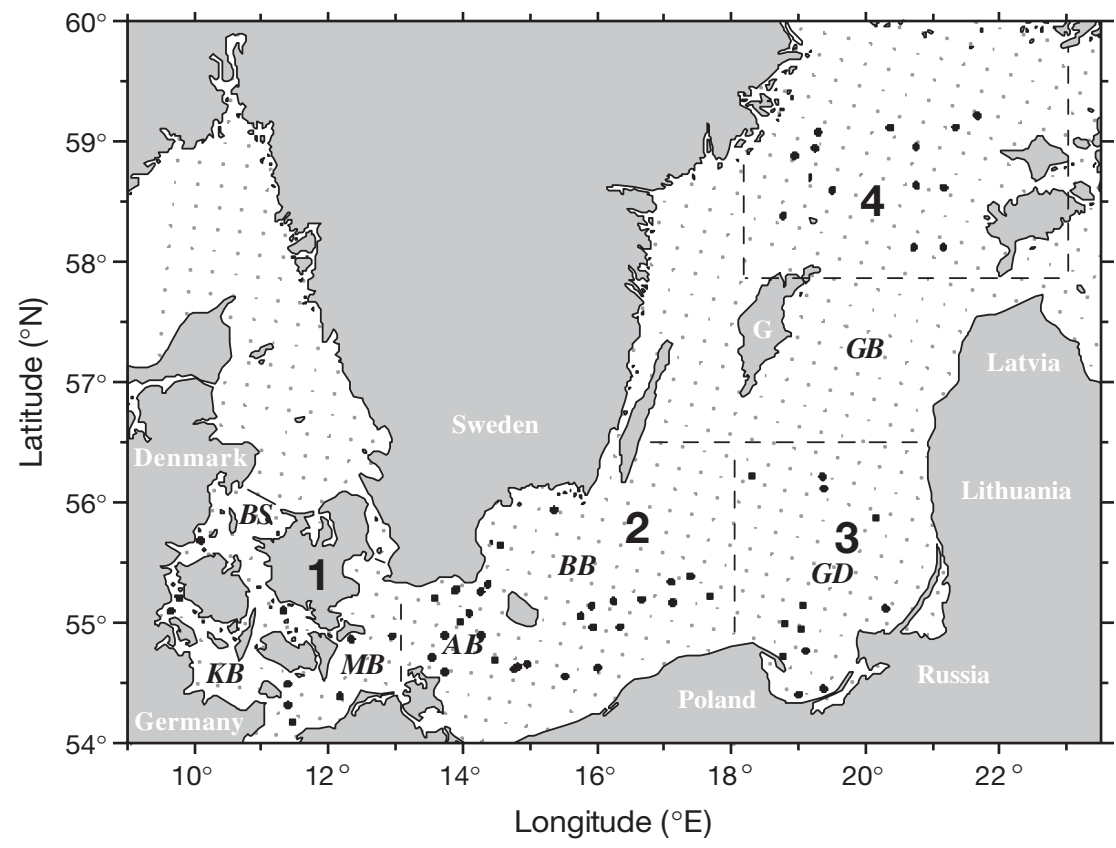

Fig. 1. Study area in the Baltic Sea with young-of-the-year (YoY) sprat Sprattus sprattus sampling sites $(\bullet)$ in October 2002. Small grey dots mark grid of satellitebased measurements of weekly sea-surface temperature; 1 to 4 : Baltic Areas 1 to 4 (within dashed lines) used in the analysis. AB: Arkona Basin; BB: Bornholm Basin; BS: Belt Seas; G: Gotland; GB: Gotland asin; GD: Gdansk Deep; KB: Kiel Bight; MB: Mecklenburg Bight

except for the Swedish vessel, which used a $40 \mathrm{~mm}$ mesh opening in the cod end $\left(L_{50}=85 \mathrm{~mm}\right.$ total length, TL). The resulting difference in gear selectivity was adjusted by applying a correction factor for each $5 \mathrm{~mm}$ length class (after Bethke et al. 1999). When present in the catch, YoY sprat always formed a distinct peak in the length frequency distribution and were thus readily distinguished from Age 1+ individuals (cut-off point 95 to $105 \mathrm{~mm} \mathrm{TL}$ ). Between 20 and 50 YoY sprat per haul were randomly selected and either immediately preserved in $95 \%$ ethanol (German, Polish, Swedish samples) or directly processed on board (Russian and Latvian samples). Processing involved length (TL, to the nearest $1 \mathrm{~mm}$ ) and weight measurements $(\mathrm{W}$, to the nearest $0.1 \mathrm{~g}$ ), followed by extraction of both sagittal

Table 1. Sprattus sprattus. Overview of young-of-the-year (YoY) sampling in October 2002 and otolith microstructure analysis (see Fig. 1 for location of areas). TL: total length (size range in $\mathrm{mm}$ ) at capture; Hauls: hauls containing YoY sprat; n: number of otoliths analysed

\begin{tabular}{|llrlrr|}
\hline Area & Sampling nation & Sampling date & TL & Hauls & n \\
\hline 1 & Germany & $15-24$ & $67-103$ & 10 & 67 \\
2 & Germany, Poland, Sweden & $7-23$ & $78-105$ & 29 & 170 \\
3 & Latvia, Poland, Russia & $20-29$ & $70-98$ & 12 & 111 \\
4 & Sweden, Russia & $11-17$ & $61-92$ & 13 & 79 \\
Total & $7-29$ & $61-105$ & 64 & 427 \\
\hline
\end{tabular}

otoliths. Since the weights of fresh and preserved specimens were not comparable, only the latter were used in analysis.

Otolith microstructure analysis. Otolith microstructure analysis was identical to that described by Baumann et al. (in press). Briefly, sagittal otoliths were mounted individually on microscopic slides with a drop of thermoplastic glue (Crystalbond ${ }^{\circledR}$ 509), polished from both sides with a $3 \mu \mathrm{m}$ lapping film (266× Imperial PSA 3M $\left.{ }^{\circledR}\right)$, and photographed under 400× magnification with a digital camera $\left(\right.$ Leica $^{\circledR}$ DC300). Otolith increments $(\mu \mathrm{m})$ were counted and measured in multi-frame digital images (ImagePro Plus 4.5.1 ${ }^{\circledR}$ ), which allowed each otolith section to be viewed in 4 to 7 different focal planes. The measurement axis always ran from the core to the post-rostrum of the otolith. A sufficient precision in increment counts was confirmed through re-readings on a subset of otoliths by the same reader $(n=48)$ and by comparing counts between 2 experienced but independent readers $(n=18)$ (as described by Baumann et al. in press). In total, otoliths of 427 individuals from 64 sampling sites were analysed (Table 1).

To study broad-scale spatial differences between YoY survivors, we defined 4 major Baltic areas (Fig. 1) to which each individual was assigned according to its catch position in October 2002. Area 1 encompassed the western Baltic Sea including the Belt Seas and the Kiel and Mecklenburg Bights. Area 2 consisted of the 2 major basins in the central Baltic, the Arkona and the Bornholm Basin, with northern and southern boundaries defined mostly by Swedish, German and Polish coastlines (W-E: 13 to $18^{\circ} \mathrm{E}$ ). In the southeastern Baltic, Area 3 represented the Gdansk Deep and southern parts of the Gotland Basin (western and northern boundaries; $18^{\circ} \mathrm{E}$ and $56.5^{\circ} \mathrm{N}$, respectively), while the most northeastern region, Area 4, contained all hauls north of Gotland Island (18 to $23^{\circ} \mathrm{E}$, 58 to $60^{\circ} \mathrm{N}$.

To validate the assumption that the subsample analysed was representative of the YoY population, the YoY length distributions in the hauls were compared to those from the otolith samples for each Baltic area. Although there were no significant differences in mean TL between field and 
otolith samples (1-way ANOVA, $p>0.05$ ), some of the $5 \mathrm{~mm}$ length classes appeared to be under- or overrepresented in our analysis. This was corrected by assigning a weighing factor to each analysed specimen according to the TL class and the Baltic area in which it was caught in October 2002. Weighing factors ranged between 0.38 (too many otoliths read in a particular length class) and 3.08 (too few otoliths analysed in a length class).

In the majority of YoY otoliths, a pronounced shift from weak and indistinct to sharp and well-defined increments was typically observed after the innermost 4 increments (range 3 to 5). This shift was assumed to correspond to the transition from non-daily increment formation during the yolk-sac stage to daily increments deposited after the onset of first-feeding, and only the latter increments were included in the analysis. Therefore, all otolith-derived age estimates hereafter refer to individual ages in days after DFF.

Prior to comparing length frequency distributions of YoY sprat among the 4 Baltic areas, we also adjusted for potential bias introduced by the different sampling periods (Table 1). Since the first haul was on 7 October 2002, all individual fish lengths were backcalculated to 6 October 2002, using the biological intercept method (Campana 1990). The otolith radius at first feeding corresponded to the distance between the core and the 4th increment; for TL, a value of $5 \mathrm{~mm}$ at first feeding was assumed, based on data of Voss et al. (2003), who found prey in the guts of 4 to $6 \mathrm{~mm}$ sprat larvae from the Bornholm Basin. The biological intercept method is independent of the slope in the otolith-fish size regression, but assumes linearity in individual otolith-fish size trajectories (Campana 1990).

Ichthyoplankton data. Spatial differences in length and timing of the sprat spawning season were inferred from ichthyoplankton data collected by the Latvian Fish Resources Agency between 1973 and 2002. A vertically operated IKS-80 net with a mouth opening of

Table 2. Sprattus sprattus. Number of YoY sprat analysed per area and 14 d DFF interval in 2002; 5-parameter Weibullcurves were not fitted for intervals containing $<4$ specimens (numbers in parentheses)

\begin{tabular}{|lcccc|}
\hline DFF interval & Area 1 & Area 2 & Area 3 & Area 4 \\
\hline 12 May-25 May & $(1)$ & $(3)$ & & \\
26 May-8 Jun & 10 & 21 & $(1)$ & $(1)$ \\
9 Jun-22 Jun & 19 & 46 & 22 & 4 \\
23 Jun-6 Jul & 13 & 72 & 45 & 17 \\
7 Jul-20 Jul & 11 & 27 & 36 & 37 \\
21 Jul-3 Aug & 13 & $(1)$ & 7 & 19 \\
4 Aug-17 Aug & & & & $(1)$ \\
Total & $66(67)$ & $166(170)$ & $110(111)$ & $78(79)$ \\
\hline
\end{tabular}

$0.5 \mathrm{~m}^{2}$ and a mesh size of $500 \mu \mathrm{m}$ was regularly deployed during 3 to 6 annual surveys, conducted mainly between March and August. The surveys covered the major sprat spawning grounds in the Baltic Sea, from the Bornholm Basin (corresponding to Area 2) and the Gdansk Deep (Area 3) to the northern part of the Gotland Basin (north of $57.5^{\circ} \mathrm{N}$ : Area 4). Unfortunately, seasonal coverage in 2002 was not sufficient to directly compare spawning and survivor patterns with those in other years. No ichthyoplankton data exist for Area 1. However, to estimate the average length and peak of sprat spawning in Areas 2 to 4, a 3parameter Gaussian function of the form

$$
N=a e^{\left[-0.5\left(\frac{D-c}{b}\right)^{2}\right]}
$$

was fitted to the mean number $(N)$ of sprat Stage 1 eggs $\left(\mathrm{n} \mathrm{m}^{-2}\right)$ per day of the year $(D)$ for all available years and surveys. The number of days with predicted egg abundances above $10 \%$ of the predicted peak abundance (parameter $a \times 10^{-1}$ ) was taken as a rough estimate of the average length of the sprat spawning season in each area.

Sea-surface temperature. Data on SST in the Baltic Sea were obtained from the 'Bundesamt für Seeschifffahrt und Hydrographie' (BSH: see www.bsh.de/ en/Marine \% 20data/Observations/Sea \%20surface $\% 20$ temperatures/index.jsp) for the years 1997 to 2002, and are based on observations of NOAA 12 and 16 satellites, with an initial spatial resolution of $1.1 \mathrm{~km}$. A multi-channel (MC) SST algorithm was applied to process the raw data, which were finally provided as weekly averages of SST on a regular $20 \times 20 \mathrm{~km}$ grid (Fig. 1). All grid-points within each of the 4 Baltic areas were later averaged to yield a mean value of SST per week and area. The mean standard deviation of temperature per area and week (May to October) was rather low, ranging between 0.9 and $1.0^{\circ} \mathrm{C}$.

Influence of temperature on otolith growth trajectories. YoY sprat were first binned into classes of similar first feeding days (DFF). We chose $14 \mathrm{~d}$ intervals starting on 12 May 2002 in order to obtain sufficient observations per DFF interval. For each Baltic area and each 14 d DFF interval containing more than 3 specimens ( $\mathrm{n}=17$, Table 2), age-increment width data (IW) were then fitted with a non-linear, 5-parameter Weibull function of the form

$$
\begin{aligned}
\mathrm{IW}= & \mathrm{IW}_{0}+a\left(\frac{c-1}{c}\right)^{\frac{1-c}{c}} \times\left[\frac{\mathrm{Age}-\mathrm{Age}_{0}}{b}+\left(\frac{c-1}{c}\right)^{\frac{1}{c}}\right]^{c-1} \\
& \times \mathrm{e}^{-\left[\frac{\left.\mathrm{Age}^{-\mathrm{Age}_{0}}+\left(\frac{c-1}{c}\right)^{\frac{1}{c}}\right]^{c-1}}{b}\right.}+\frac{c-1}{c}
\end{aligned}
$$


with parameters $a, b, c, \mathrm{IW}_{0}$, and Age $\mathrm{e}_{0}$ being estimated through iteration (SigmaPlot ${ }^{\circledR}$ 9.0). The function appropriately modelled the typical features of the YoY otolith trajectory, i.e. the initial steep increase, the local maximum, and the gradual decrease in increment width. The parameters $\mathrm{Age}_{0}, \mathrm{IW}_{0}+a_{1}, c$ and $b$ corresponded to (1) age at peak increment width, (2) peak increment width, (3) increment width at first inflection point, and (4) the age at second inflection point, respectively.

Within each Baltic area, mean weekly SST in 2002 was taken as a proxy for the average temperature history of YoY populations, assuming that the majority of survivors originated from those broadly defined regions where they were sampled in October 2002. To test whether the variability in Weibull parameters (i.e. the shapes of the otolith growth trajectories) could be explained by differences in temperature experienced, SST was averaged for each Baltic area over periods of 10, 20, 30, 40, 50, 60 and $70 \mathrm{~d}$ starting from the middle of each DFF interval. The different values for each Weibull parameter comprised independent observations and were subsequently regressed linearly on mean area- and DFF-specific SST ( $\mathrm{n}=17$ for each of the 7 periods, SPSS $^{\odot} 10.0 .7$ ).

To test whether significant differences in mean $W$, TL, and DFF existed between YoY sprat from different Baltic areas, 1-way ANOVAs were performed, with subsequent LSD (least-significant difference) (homogeneous variances) or Dunnett-T3 (inhomogeneous variances) post-hoc tests for significant differences between areas $\left(\right.$ SPSS $^{\odot}$ 10.0.7). To test different pairs of linear regression lines for significant differences in slope and intercept, the method of Zar (1984) was applied (implemented in GraphPad ${ }^{\circledR}$ Prism software). For all statistical tests, significance is hereafter reported only for $\mathrm{p}<0.05$.

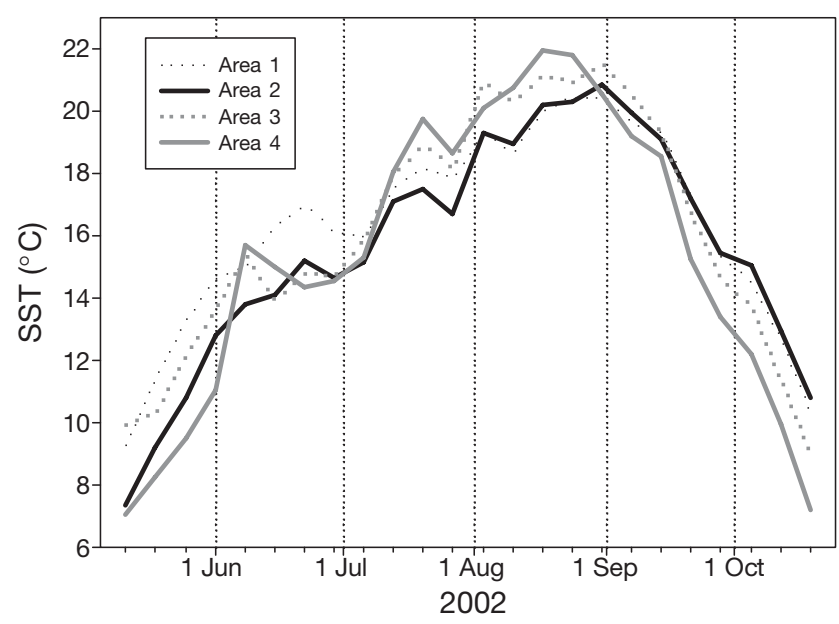

Fig. 2. Mean weekly sea-surface temperature (SST) in Baltic Areas 1 to 4 derived from satellite data. See Fig. 1 for location of areas

\section{RESULTS}

Mean SST during the second week in May 2002 ranged between 7.0 and $9.9^{\circ} \mathrm{C}$ in Areas 1 to 4 , increased steadily thereafter until the last week in August $\left(20.3-21.8^{\circ} \mathrm{C}\right)$, and decreased sharply again to $6.9-10.0^{\circ} \mathrm{C}$ at the end of October 2002 (Fig. 2). The variability in SST between areas was surprisingly low; area differences in mean weekly SST ranged only between 0.8 and $3.8^{\circ} \mathrm{C}$ (mean $=2.2^{\circ} \mathrm{C}$ ). Surface warming was delayed, while autumn cooling was more rapid in Area 4 relative to the other Baltic areas. However, between mid-July and the end of August 2002, SST was highest in Area 4 (Fig. 2), an exceptional situation compared to the previous 5 yr (1997 to 2001).

The analysis of YoY weights, performed separately for each $5 \mathrm{~mm}$ TL class ( 75 to $95 \mathrm{~mm}$ ), revealed that individuals in the western and central Baltic (Areas 1 and 2) were significantly heavier than their conspecifics in the eastern Baltic (Areas 3 and 4) for all 4 TL classes studied. The relationship between otolith radius (OR, in $\mu \mathrm{m})$ and TL did not deviate significantly from linearity for pooled $\left(\mathrm{TL}=23.01+0.104 O R, \mathrm{r}^{2}=0.76, \mathrm{n}=426\right.$ ) or for the separately analysed Baltic areas.

Length frequency distributions of YoY sprat differed considerably between the Baltic areas (Fig. 3). Mean TL on 6 October was significantly higher in western and central Areas 1 and 2 (85.1 and $86.9 \mathrm{~mm}$, respectively) than in Area 3 (79.8 $\mathrm{mm})$, while individuals in Area $4(73.0 \mathrm{~mm})$ were significantly the smallest YoY survivors. The broadest and narrowest TL distribution was in Areas $1(\mathrm{SD}=8.07 \mathrm{~mm})$ and $2(\mathrm{SD}=5.23 \mathrm{~mm})$, respectively, whereas Areas 3 and 4 showed intermediate TL variability (SD = 7.76 and $6.58 \mathrm{~mm}$, respectively). A characteristic shift was also apparent in the DFF distributions, which showed increasing mean DFFs and narrowing distributions from western to northeastern Baltic areas (Fig. 4). The mean DFF of YoY sprat in Area 4 (13 July) occurred 19 d later than in Areas 1 and 2 (19 d) and Area 3 (11 d), while individuals in Area 3 were significantly younger than those in Area 2 by 8 d. The main 'window of survival' in 2002, here characterised by the difference between the 90th and 10th percentile of DFFs, narrowed from $58 \mathrm{~d}$ in Areas 1 to 36, 31 and $27 \mathrm{~d}$ in Areas 2, 3 and 4, respectively (Fig. 4).

Pooled data on sprat egg abundance (1973 to 2002) were very heterogeneous in all Baltic areas, both in terms of absolute numbers as well as with regard to the time of the year that eggs appeared in the water column. This was probably due to a combination of high inter-annual variability, spatial patchiness, and low sampling intensity (only 3 to 6 surveys $\mathrm{yr}^{-1}$ ). Although the 3-parameter Gaussian functions significantly fitted the data in Areas 2 to 4 , the curves only explained $37 \%$ 
(Areas 2 and 3) and 23\% (Area 4) of the overall variability in seasonal sprat egg abundance. Mean predicted peak abundance of sprat eggs showed a consistent shift to later dates from Area 2 (3 June) and Area 3

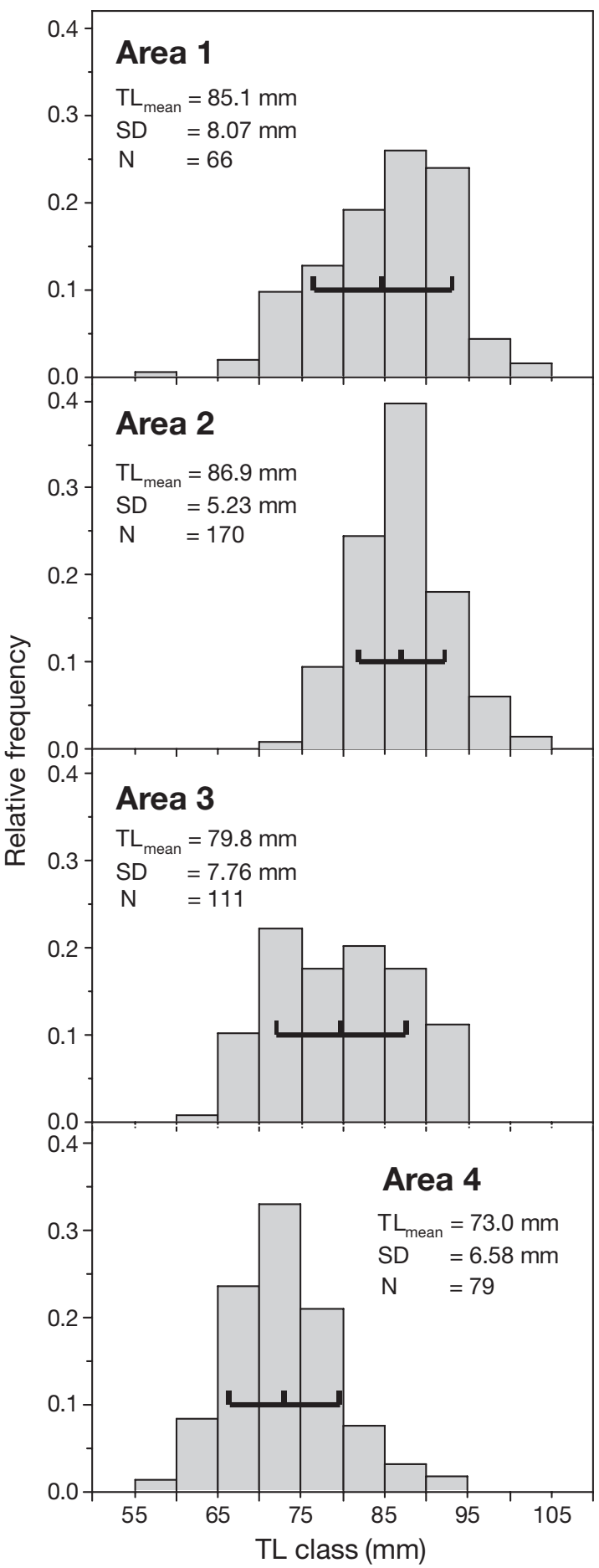

Fig. 3. Sprattus sprattus. Relative total length (TL) frequency distribution of YoY sprat back-calculated to 6 October 2002 in Baltic Areas 1 to 4 . Mean \pm SD indicated by whiskers on black bars. N: number of analysed specimens

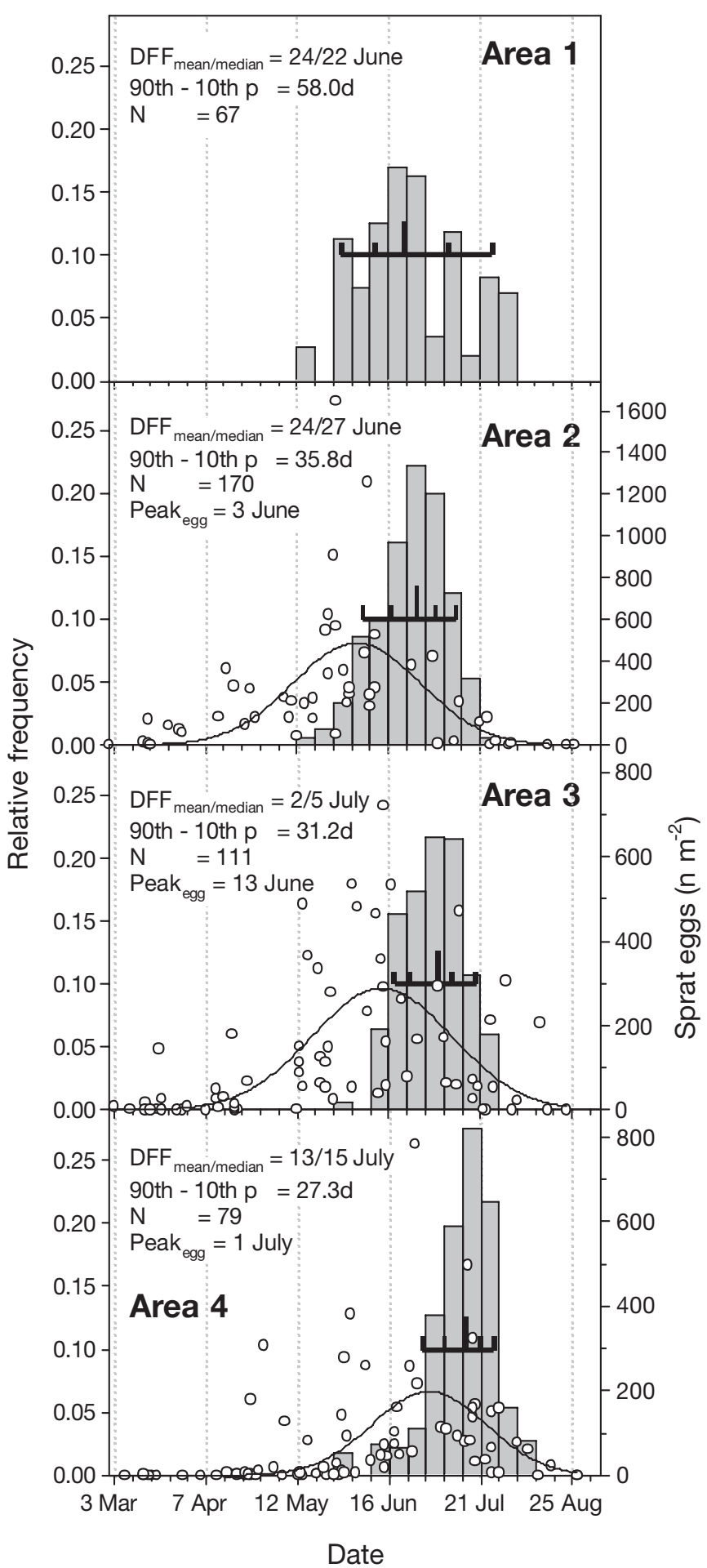

Fig. 4. Sprattus sprattus. Distributions of otolith-based, backcalculated days of first feeding (DFF, grey bars) of YoY sprat caught in October 2002 in Baltic Areas 1 to 4 in relation to seasonal abundance of sprat eggs (Stage 1) derived from ichthyoplankton hauls between 1973 and 2002 (o). Egg data fitted with 3-parameter Gaussian function (black curve). Median DFF and 10th, 25th, 75th and 90th percentiles indicated by long and short whiskers on black bars, respectively. $\mathrm{N}$ : number of analysed specimens; $\mathrm{n}$ : number of eggs $\mathrm{m}^{-2}$ 


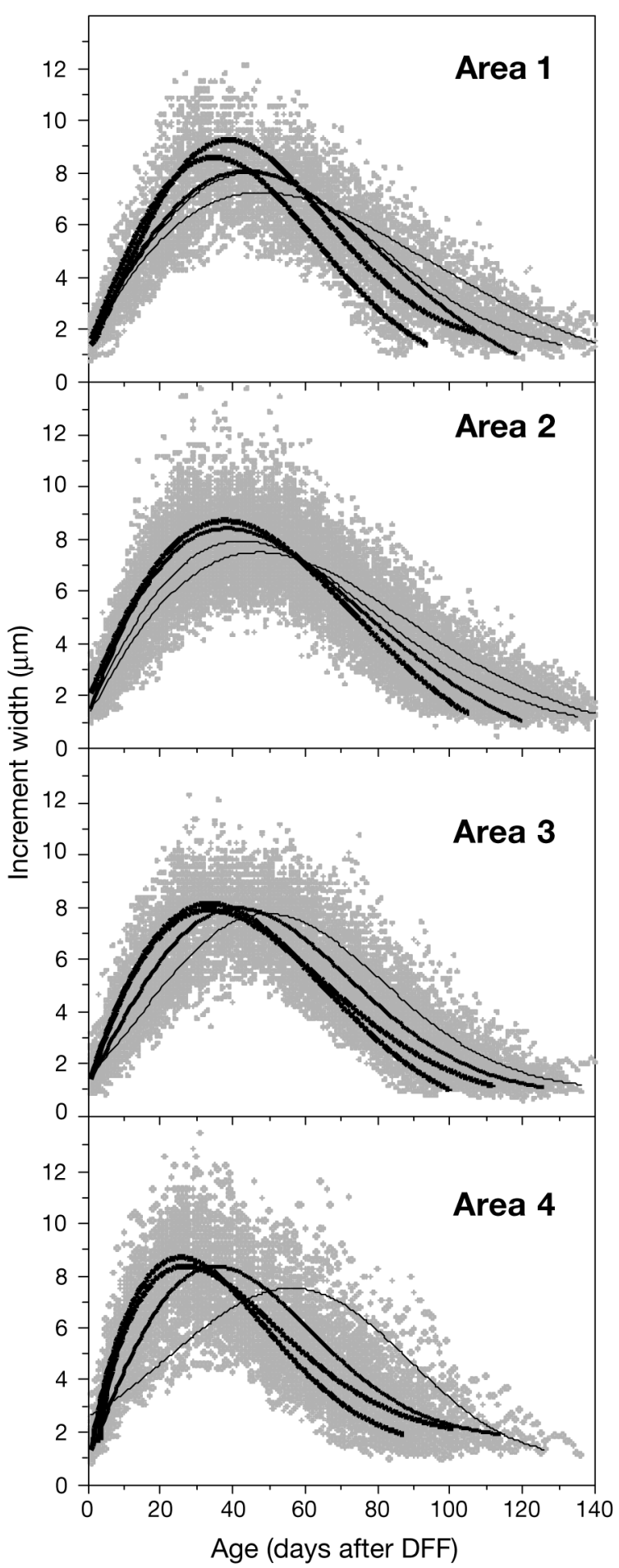

Fig. 5. Sprattus sprattus. Individual age-increment widths (•) and mean predicted otolith growth trajectories of YoY sprat (black curves) from Baltic Areas 1 to 4 in 2002. Within each area, data grouped into fortnightly DFF intervals based upon back-calculated DFF and fitted with Weibull 5-parameter curve. Lines increase in thickness from earliest to latest DFFs (i.e. $\mathrm{DFF}_{1}$ : 26 May-25 June; $\mathrm{DFF}_{2}$ : 9-22 June, $\mathrm{DFF}_{3}$ : 23 June-6 July; $\mathrm{DFF}_{4}$ : 7-20 July; $\mathrm{DFF}_{5}$ : 21 July-3 August)
(13 June) to Area 4 (1 July). The longest mean spawning season was for Area 3 with 114 d, followed by Area 2 (103 d) and Area 4 (92 d, Fig. 4).

Despite the expected high variability in individual otolith growth trajectories, increment width-at-age differed systematically between Baltic areas and between individuals from different DFF intervals. This was inferred from significant 5-parameter Weibull regressions that fitted the data well and explained between 76 and $86 \%$ of the overall variability in area- and DFFspecific otolith trajectories (Fig. 5). Within each area, the initial increase during the larval stage and the gradual decrease in otolith growth rates during the juvenile stage were both notably steeper in individuals born later in the season compared to their earlier born conspecifics (Fig. 5). Within each of the 3 latest DFF intervals, individuals from Area 4 appeared to have higher initial otolith growth rates, which were again followed by a steeper decline in increment width relative to YoY survivors from other Baltic areas.

A total of 17 area- and DFF-specific Weibull-curves could be fitted (Figs. 5 \& 6), and the 17 values of each parameter were then linearly regressed on SST, with the latter averaged over periods of 10 to $70 \mathrm{~d}$. Significant linear relationships were found for all 7 periods, but strongest temperature correlations were observed for parameters $\operatorname{Age}_{0}\left(\mathrm{r}_{\text {max }}^{2}=0.74\right)>b\left(\mathrm{r}^{2}\right.$ max $\left.=0.51\right)>$ $\mathrm{IW}_{0}+a\left(\mathrm{r}_{\text {max }}^{2}=0.38\right)$ in relation to $\mathrm{SST}_{20}$ and $\mathrm{SST}_{30}$, suggesting that the temperature experienced during the first $30 \mathrm{~d}$ after DFF (larval stage) had most influence on the shape of YoY otolith trajectories. The increment width at the first inflection point $(c)$ was not significantly related to SST. While age at peak increment width $\left(\mathrm{Age}_{0}\right)$ and age at the second inflection point $(b)$ were negatively correlated to temperature, predicted peak increment width $\left(\mathrm{IW}_{0}+a\right)$ significantly increased with increasing SST (Fig. 6: shown only for $\mathrm{SST}_{30}$ ). However, the latter effect was much weaker, and thus otolith size at the age of peak increment width $\left(\mathrm{OS}_{\mathrm{Age}_{0} \text { ' }}\right.$ $\mu \mathrm{m})$ also decreased linearly with decreasing Age $_{0}$ $\left(\mathrm{OS}_{\mathrm{Age}_{0}}=61.5+4.3 \mathrm{Age}_{0}, \mathrm{r}^{2}=0.93, \mathrm{n}=17\right)$.

To test the temperature effect on YoY growth independently of the Weibull regressions, mean daily somatic growth rates during the first $30 \mathrm{~d}$ after DFF (biological intercept method) were regressed against the corresponding mean SST values. Significant positive relationships between somatic growth rates and temperature were found for all Baltic areas and explained between 33 and $54 \%$ of the overall variability (Fig. 7). Slopes increased non-significantly from Area 1 to Area 4 , with a common slope of $0.063 \mathrm{~mm} \mathrm{~d}^{-1}{ }^{\circ} \mathrm{C}^{-1}$. The regression intercept of Area 2 differed significantly from those for the other areas and indicated that temperature-adjusted larval growth was highest in Area 2 followed by Areas 4, 1, and 3 (Fig. 7). 

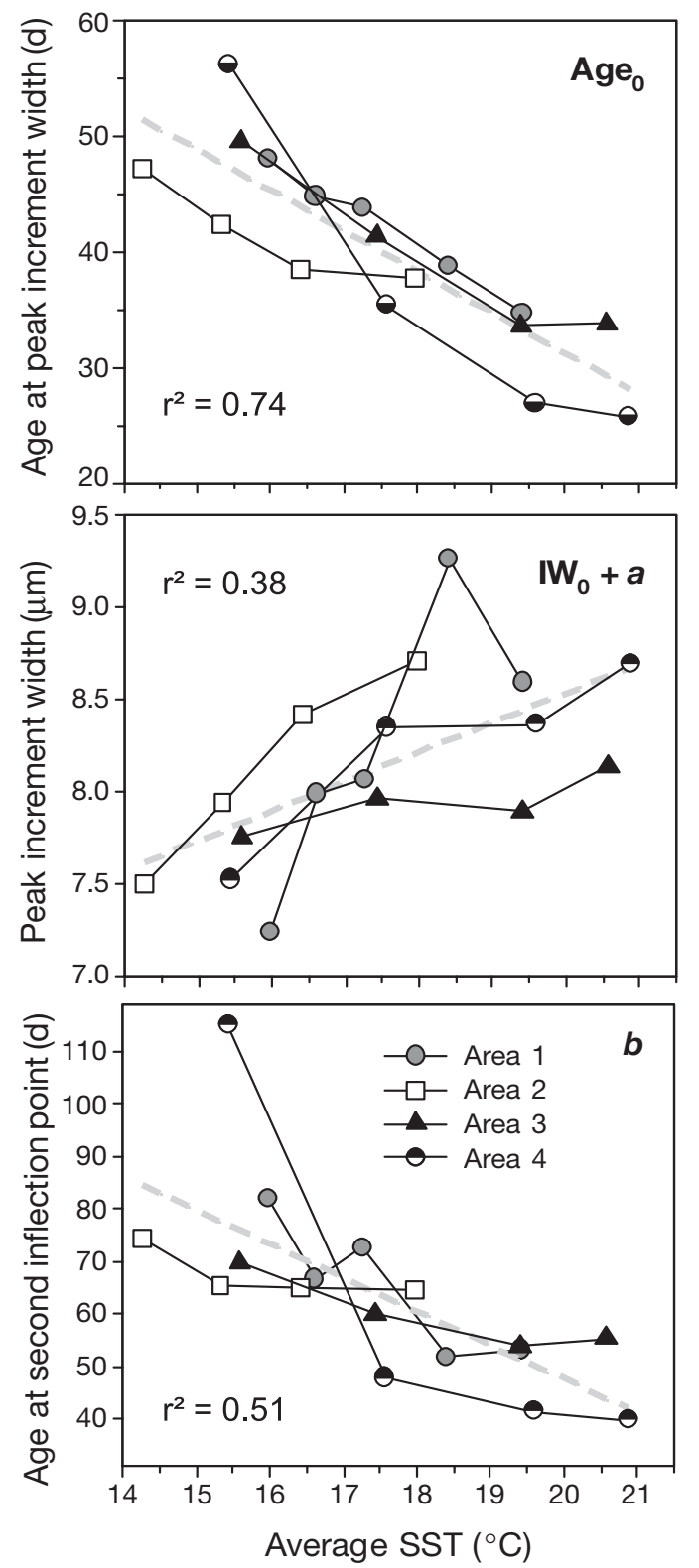

Fig. 6. Sprattus sprattus. Relationship between Weibull parameters $\mathrm{Age}_{0}$ (age at peak increment width), $\mathrm{IW}_{0}+a$ (peak increment width), $b$ (age at second inflection point) and average sea-surface temperature (SST) during the first $30 \mathrm{~d}$ after DFF. Within each Baltic area, between 4 and 5 Weibull-curves (total $\mathrm{n}=17$ ) were fitted to age-increment width data, pooled per $14 \mathrm{~d}$ DFF interval. Dashed lines and $\mathrm{r}^{2}$-values refer to significant linear regressions of all data points in each plot

\section{DISCUSSION}

\section{Temperature histories based on SST}

The temperature histories explained remarkably large parts of the spatial and temporal variability in YoY growth patterns, despite the relatively coarse resolution of satellite-based SSTs (weekly and areal

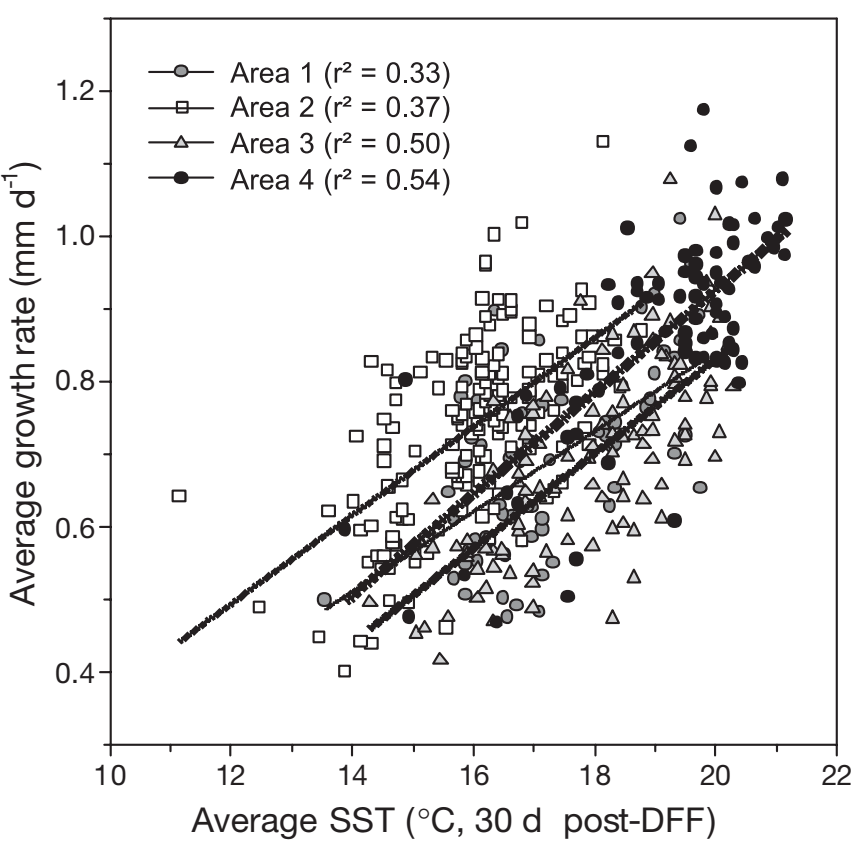

Fig. 7. Sprattus sprattus. Linear relationships between average, back-calculated somatic growth rate during larval stage and average SST ( 30 d after DFF) within Baltic Areas 1 to 4 . All relationships were significant at the $p=0.05$ level. Regression lines increase in thickness from Areas 1 to 4

means) and our inherent assumption that individuals originated from and remained within those Baltic areas in which they were caught as YoY in October 2002. Because sprat spawning is known to take place in all these 4 Baltic areas (Sjöblom \& Parmanne 1976, Grauman \& Krenkel 1986), and we purposely defined only 4 (albeit rather large rectangles to allow for some random larval advection), we believe this assumption to be justified. In addition, spatial variability in SST was very low compared to seasonal temperature differences, implying only small errors due to inclusion of individuals originating from neighbouring regions outside the defined rectangles.

Large-scale larval transport across areas, on the other hand, could have introduced a more serious bias into SST-based temperature histories. This was addressed recently by Hinrichsen et al. (2005), who used long-term hydrodynamic modelling to estimate the general mixing probabilities of sprat larvae in the Baltic Sea. Hinrichsen et al. (2005) concluded that a high spatial overlap may only occur between larvae from the Arkona and Bornholm Basins, which was the main reason for combining these 2 spawning grounds in the present study. In contrast, estimated mixing probabilities between the Bornholm and Gotland Basins larvae were consistently at low levels. Only the Gdansk Deep (Area 3) was identified as a region in which larvae from neighbouring regions potentially accumulate, 
including those from eastern parts of the Bornholm Basin (Area 2). However, similar Lagrangian simulations by Baumann et al. (in press) revealed that only early born larvae from the Bornholm Basin could have been transported as far as the adjacent Gdansk Deep. The present study, on the other hand, found subtle indications for a partial overlap between central and eastern YoY sprat. In contrast to Areas 1, 2 and 4, the TL and DFF distributions in Area 3 conspicuously lacked a clear mode (Figs. 3 \& 4), which could have resulted from mixing 2 slightly different YoY groups. This, however, does not invalidate the overall suitability of using satellite-based SSTs to approximate the temperature history of Baltic YoY sprat. It is likely that the robust signal already detected with SST would have been even more pronounced had the real temperature experience or a closer proxy been available.

\section{Spatial differences between Baltic YoY sprat}

The finding that sprat recruits in the eastern and northeastern areas were significantly smaller than their conspecifics in the central and western parts of the Baltic Sea is consistent with many working reports that studied age-length relationships in Baltic sprat (Lindquist 1971, Aps et al. 1988) or combined these with otolith macrostructure analyses (Grygiel 1978). For example, Aps et al. (1981) and Shvetsov et al. (1992) measured the innermost otolith growth zone prior to the first winter ring, and concluded that lengths of YoY sprat decrease from southwestern to northeastern Baltic regions.

Differences in body size could simply result from shifts in spawning seasons (Shvetsov et al. 1992, Grygiel 1999). This, however, would expose the offspring to seasonally different environmental conditions and thus probably modify the spatial heterogeneity among survivors (e.g. García et al. 2003). Firstly, the present study has proved that mean spawning effort of sprat is indeed shifted by almost 1 mo from central to northeastern Baltic spawning grounds. Assuming that sprat reproduction is cued by temperature, as for example in the bay anchovy Anchoa mitchilli (Lapolla 2001), this shift is most reasonably explained by the consistently delayed spring warming in the northeastern vs. central Baltic areas. Secondly, the different spawning periods corresponded well to the observed shift in DFF distributions of sprat survivors in 2002, with an offset in mean DFFs between central and northeastern individuals of $19 \mathrm{~d}$. Assuming spatially and temporally invariable growth patterns, a delay of $19 \mathrm{~d}$ could have accounted for a TL difference of only $6.7 \mathrm{~mm}$, whereas the mean TL of YoY survivors in October 2002 differed by $13.9 \mathrm{~mm}$ (Areas 2 and 4, Fig. 3). Therefore, YoY growth varied substantially between Baltic areas and DFF periods, induced by either different environmental conditions and/or differences in growth capacity between potential subpopulations.

\section{Influence of temperature on growth trajectories}

Depending on both the time of first feeding and the Baltic area, YoY otolith growth patterns indeed showed substantial variability. Within a given area, the initial increase in growth rates (corresponding to larval stage) was notably steeper in later born individuals, while within a given DFF interval the area effect consisted of a similar but less pronounced increase in larval growth from western/central to eastern/northeastern Baltic regions. In both cases, higher larval growth rates were always followed by a steeper decline in growth after the peak, and this similarity indicated that growth trajectories were influenced by a common determinant such as temperature, which varied similarly in time and space (Folkvord et al. 2004).

The strong correlations between SST and the estimated Weibull parameters confirmed the key importance of temperature for somatic growth of YoY sprat, provided that growth-independent temperature effects on otoliths (Huuskonen \& Karjalainen 1998) were negligible. The characteristic patterns allowed several further conclusions: (1) the shape of the otolith trajectory was determined mainly by the temperature experienced throughout the larval and early juvenile stage; this is consistent with many field (Crecco \& Savoy 1985, Baumann et al. in press) and laboratory (Otterlei et al. 2002) studies. (2) Sprat larvae born later in the season experienced higher temperatures and therefore had broader peak increments, which they reached earlier after DFF (Fig. 8) and at lower otolith sizes. Thus, fast growing sprat larvae were smaller at the point of maximum growth, although the magnitude of the effect was probably exaggerated, because faster growing individuals often form relatively smaller otoliths (Campana 1990, Baumann et al. 2005). However, temperature-mediated higher growth rates of larvae born later in the season are well documented for temperate fish species (e.g. Rice et al. 1987) and appear positively related to cohort survival (Limburg 1996, Fowler \& Jennings 2003). Importantly, the subsequent decline in growth rates occurred independently of the seasonal temperature curves, i.e. most increment widths decreased before the end of August, the time when SST started to decline. This could arise from ontogenetic constraints of otolith and somatic growth, i.e. beyond a certain size or developmental stage (e.g. metamorphosis), sprat juveniles cease to grow faster in length despite of still rising ambient 


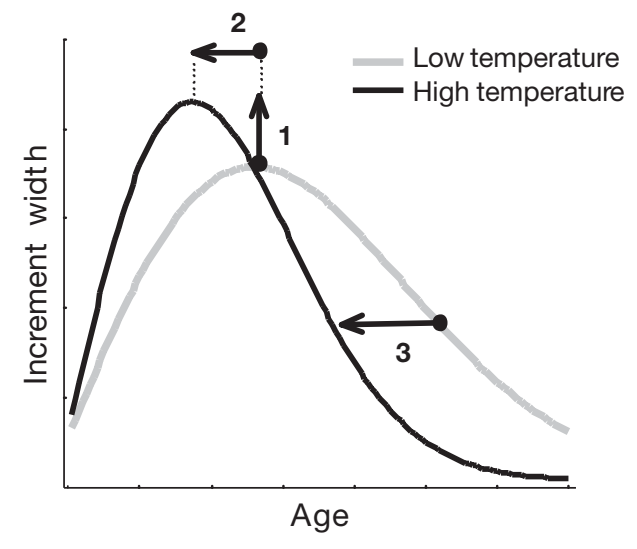

Fig. 8. Sprattus sprattus. Conceptual diagram illustrating the 3 effects (arrows) of temperature on shape of otolith growth trajectory throughout larval and juvenile stages (ca. first $5 \mathrm{mo}$ ). Individuals experiencing higher temperatures have broader peak increments (1), which they reach earlier after DFF (2), and are also younger at the post-peak inflection point of their otolith trajectory (3)

temperatures. (3) Thus, in effect, higher temperatures experienced during the larval stage shortened the period of faster growth, as suggested by the negative relationship between age at the second inflection point (parameter $b$ ) and temperature (Fig. 8). Hence, the observed trade-off between higher larval, but more rapidly declining juvenile growth rates may have resulted in the remnant TL differences between YoY sprat that were not explained by shifts in spawning or DFF distributions. (4) Seasonal temperature variability in 2002 (spring to autumn) was about 6 times greater than spatial temperature differences between Baltic areas, which is consistent with the strong DFF but weaker area effect on YoY growth patterns. The lack of correlation between SST and increment width at the first inflection point (parameter $c$ ) was rather due to inappropriate temperature values, given that the first inflection point was predicted very early after first feeding ( 1 to $3 \mathrm{~d}$ ). Thus, this parameter was probably influenced by temperatures during the yolk-sac stage (Pepin et al. 2001), when sprat larvae in the Baltic Sea still occur at intermediate water depths (Wieland \& Zuzarte 1991) and probably experience temperatures that are poorly reflected by SST.

The present approach of fitting 5-parameter Weibull functions to area- and DFF-specific increment widthat-age data produced curves similar to those published by Bartsch (2002), who incorporated a temperaturedependent term into logistic growth functions in order to model growth of larval and juvenile mackerel Scomber scombrus. In the case of sprat growth trajectories, the use of Weibull functions was advantageous over the derivative of the logistic formulation, because it allowed for different curvatures and asymmetric inflection points left and right of the growth peak. How- ever, both studies suggest that growth trajectories of fishes throughout their first year of life follow similar ontogenetic patterns of increasing larval and decreasing juvenile growth rates, which are modified by ambient temperature conditions (Fig. 8). Over the last $30 \mathrm{yr}$, a wealth of corroborating otolith trajectories has been published for a number of species in different marine systems, although most studies encompassed only parts of the full 0-group pattern (e.g. Meekan \& Fortier 1996, Folkvord et al. 1997, Fowler \& Jennings 2003, Allain et al. 2003, but see Kurita et al. 2004 for exception).

In summary, the substantial length differences between northeastern Baltic YoY recruits and their conspecifics in central and western regions of the Baltic Sea may have resulted initially from the temperatureinduced delay in spawning activity in Area 4, which probably entailed the shifted DFF distribution of YoY survivors. This in turn led to higher temperatures experienced by individuals in Area 4 during the larval and early juvenile stage, and thus elicited higher larval but much lower juvenile growth rates-the latter amplified by the more rapid temperature decline in autumn in the northeastern Baltic. Despite the narrower DFF distribution in Area 4, the variability in the observed TLs was comparable to that in the other Baltic areas, perhaps because higher temperatures experienced also appear conducive to higher growth variability (Houde 1989). On the other hand, the narrower DFF distribution appeared merely to reflect the shorter mean spawning season of northeastern Baltic sprat, suggesting that in 2002 the relative (in contrast to the absolute) 'survival window' was not substantially smaller than in other Baltic sprat spawning grounds. The question remains, however, as to whether the outstandingly high growth rates of northeastern Baltic sprat larvae were only a consequence of the atypically high summer temperatures in this area in 2002, or whether this pattern is general. After adjusting for the effects of temperature, larval residual growth rates were highest for YoY survivors in the central Baltic Sea (Area 2, Fig. 7); this could have been due to a number of unresolved factors, most importantly potential spatial differences in food availability.

During the last 3 decades, a large body of papers, working reports and episodic observations has remarked on the obvious existence of a west-east gradient in Baltic sprat morphology (e.g. Grygiel 1978, Aps et al. 1981, Aro 1989), which was fully corroborated by the present study. The consistently greater lengths and weights of sprat individuals in the western and central, compared to the eastern and northeastern Baltic Sea have stimulated the recurring idea of at least 2 existing subpopulations of Baltic sprat with different growth characteristics and thus potential implications for the current single-stock management practice (Aps 1991, 
ICES 2005a). However, the results of the combination of otolith microstructure analysis and satellite-based SSTs used in the presnt study suggest that most regional differences in the length of Baltic YoY sprat are primarily a consequence of spatial and temporal differences in temperature experienced, thereby highlighting the key role of this environmental factor in growth variability in marine fishes.

Acknowledgements. We are greatly indebted to Dr. N. Håkansson, Dr. W. Grygiel, D. Stepputtis, as well as all the officers and crews of the RV 'Argos' (Sweden), RV 'Atlantniro' (Russia, Latvia), RV 'Baltica' (Poland), and FRV 'Solea' (Germany), who facilitated this truly international study through their invaluable assistance during field sampling. We are also grateful to P. Löwe from the 'Bundesamt für Seeschifffahrt und Hydrography' (BSH) for providing the satellite data on Baltic sea-surface temperature. The manuscript has benefited from the constructive criticism of 3 anonymous reviewers. This study was partly funded by the GLOBEC-Germany program (FKZ 03F0320E).

\section{LITERATURE CITED}

Allain G, Petitgas P, Grellier P, Lazure P (2003) The selection process from larval to juvenile stages of anchovy (Engraulis encrasicolus) in the Bay of Biscay investigated by Lagrangian simulations and comparative otolith growth. Fish Oceanogr 12:407-418

Aps R (1991) The Baltic sprat stock units: myth or reality? Int Counc Explor Sea CM 1991/J:9:5

Aps R, Falk U, Oeberst R (1981) Morphological variability of otolith growth zones in the Baltic sprat. Fisch-Forsch 19: 27-30 (in Russian)

Aps R, Shirokov S, Ustinova LA (1988) Variability of the Baltic sprat growth. Fisch-Forsch Rostock 26(2):77-81 (in Russian)

Aro E (1989) A review of fish migration patterns in the Baltic. Rapp P-V Réun Cons Int Explor Mer 190:72-96

Bagge O, Thurow F, Steffensen E, Bray J (1994) The Baltic cod. Dana 10:1-28

Bartsch J (2002) Modelling the temperature mediation of growth in larval fish. Fish Oceanogr 11:310-314

Baumann H, Pepin P, Davidson FJM, Mowbray F, Schnack D, Dower JF (2003) Reconstruction of environmental histories to investigate patterns of larval radiated shanny (Ulvaria subbifurcata) growth and selective survival in a large bay of Newfoundland. ICES J Mar Sci 60:243-258

Baumann, H, Peck MA, Herrmann JP (2005) Short-term decoupling of otolith and somatic growth induced by food level changes in post-larval Baltic sprat, Sprattus sprattus. Mar Freshw Res 56:539-547

Baumann H, Hinrichsen HH, Voss R, Stepputtis D, Grygiel W, Clausen LW, Temming A (in press) Linking growth to environmental histories in central Baltic young-of-theyear sprat, Sprattus sprattus: an approach based on otolith microstructure analysis and hydrodynamic modeling. Fish Oceanogr

Bethke E, Arrhenius F, Cardinale M, Håkansson N (1999) Comparison of the selectivity of three pelagic sampling trawls in a hydroacoustic survey. Fish Res 44:15-23

Campana S (1990) How reliable are growth back-calculations based on otoliths? Can J Fish Aquat Sci 47:2219-2227
Crecco VA, Savoy TF (1985) Effects of biotic and abiotic factors on growth and relative survival of young American shad, Alosa sapidissima, in the Connecticut River. Can J Fish Aquat Sci 42:1640-1648

Folkvord A, Rukan K, Johannessen A, Moksness E (1997) Early life history of herring larvae in contrasting feeding environments determined by otolith microstructure analysis. J Fish Biol 51(Suppl A):250-263

Folkvord A, Johannessen A, Moksness E (2004) Temperaturedependent otolith growth in Norwegian spring-spawning herring (Clupea harengus L.) larvae. Sarsia 89:297-310

Fowler AJ, Jennings PR (2003) Dynamics in 0+ recruitment and early life history for snapper (Pagrus auratus, Sparidae) in South Australia. Mar Freshw Res 54: 941-956

Garciá A, Cortés D, Ramírez T, Giráldez A, Carpena A (2003) Contribution of larval growth rate variability to the recruitment of the Bay of Málaga anchovy (SW Mediterranean) during the 2000-2001 spawning season. Sci Mar 67:477-490

Grauman G, Krenkel K (1986) Investigations about the dynamic of spawning processes of the Baltic sprat in 1984. Int Counc Explor Sea CM 1986/J:17:10

Grimm SK, Herra T (1984) Spawning cycles of southern Baltic fishes based on surveys of eggs and larvae. Int Counc Explor Sea CM 1984/J:30:

Grygiel W (1978) Growth pattern of the sprat caught in the southern Baltic in 1974-77. Int Counc Explor Sea CM 1978/J:12:20

Grygiel W (1999) The distribution of gonad maturity stages, and sex ratio of sprat caught in the Polish EEZ in 1998. Working document of the ICES Baltic Fisheries Assessment Working Group (WGBFAS), p 1-4

Heath MR (1992) Field investigations of the early life stages of marine fish. Adv Mar Biol 28:1-174

Hinrichsen HH, Möllmann C, Voss R, Köster FW, Kornilovs G (2002) Biophysical modeling of larval Baltic cod (Gadus morhua) growth and survival. Can J Fish Aquat Sci 59: 1858-1873

Hinrichsen HH, Kraus G, Voss R, Stepputtis D, Baumann H (2005) The general distribution pattern and mixing probability of Baltic sprat juvenile populations. J Mar Syst 58:52-66

Houde ED (1989) Comparative growth, mortality, and energetics of marine fish larvae: temperature and implied latitudinal effects. Fish Bull (Wash DC) 87:471-495

Huuskonen H, Karjalainen J (1998) A preliminary study on the relationships between otolith increment width, metabolic rate and growth in juvenile whitefish (Coregonus lavaretus L.). Arch Hydrobiol 142:371-183

ICES (International Council for Exploration of the Sea) (2005a) Report of the Baltic Fisheries Assessment Working Group (WGBFAS), Int Counc Explor Sea CM 2005/ ACFM:19, Copenhagen

ICES (International Council for Exploration of the Sea (2005b) Report of the Baltic International Fish Survey Working Group (WGBIFS), Int Counc Explor Sea CM 2005/ G:08:313, Copenhagen

Kornilovs G, Sidrevics L, Dippner JW (2001) Fish and zooplankton interaction in the Central Baltic Sea. ICES J Mar Sci 58:579-588

Köster FW, Möllmann C (2000) Trophodynamic control by clupeid predators on recruitment success in Baltic cod? ICES J Mar Sci 57:310-323

Köster FW, Hinrichsen HH, Schnack D, St John MA and 7 others (2003) Recruitment of Baltic cod and sprat stocks: identification of critical life stages and incorporation of 
environmental variability into stock-recruitment relationships. Sci Mar 67:129-154

Kurita Y, Nemoto Y, Oozeki Y, Ken-Ichi H, Ida H (2004) Variations in patterns of daily changes in otolith increment widths of $0+$ Pacific saury, Cololabis saira, off Japan by hatch date in relation to the northward feeding migration during spring and summer. Fish Oceanogr 13:54-62

Lapolla AE (2001) Bay anchovy Anchoa mitchilli in Narragansett Bay, Rhode Island. II. Spawing season, hatch-date distribution and young-of-the-year growth. Mar Ecol Prog Ser 217:103-109

Limburg KE (1996) Growth and migration of 0-year American shad (Alosa sapidissima) in the Hudson river estuary: otolith microstructural analysis. Can J Fish Aquat Sci 53: $220-238$

Lindquist A (1971) Contribution to the knowledge of the Baltic sprat (Sprattus sprattus). Int Counc Explor Sea CM 1971/H:19:9

MacKenzie BR, Alheit J, Conley DJ, Holm P, Kinze CC (2002) Ecological hypotheses for a historical reconstruction of upper trophic level biomass in the Baltic Sea and Skagerrak. Can J Fish Aquat Sci 59:173-190

Meekan MG, Fortier L (1996) Selection for fast growth during the larval life of Atlantic cod Gadus morhua on the Scotian shelf. Mar Ecol Prog Ser 137:25-37

Möllmann C, Köster FW (1999) Food consumption by clupeids in the Central Baltic: evidence for top-down control? ICES J Mar Sci 56(Suppl):100-113

Muus BJ, Nielsen JG (1999) Die Meeresfische Europas in Nordsee, Ostsee und Atlantik. Franckh-Kosmos Verlag, Stuttgart

Nissling A, Müller A, Hinrichsen HH (2003) Specific gravity and vertical distribution of sprat eggs in the Baltic Sea. J Fish Biol 63:280-299

Otterlei E, Folkvord A, Nyhammer G (2002) Temperature

Editorial responsibility: Howard I. Browman (Associate Editor-in-Chief), Storebø, Norway dependent otolith growth of larval and early juvenile Atlantic cod (Gadus morhua). ICES J Mar Sci 59:401-410

Pepin P, Dower JF, Benoit HP (2001) The role of measurement error on the interpretation of otolith increment width in the study of growth in larval fish. Can J Fish Aquat Sci 58: 2204-2212

Ré P, Gonçalves E (1993) Growth of sprat Sprattus sprattus larvae in the German Bight (North Sea) as inferred by otolith microstructure. Mar Ecol Prog Ser 96:139-145

Rice JA, Crowder LB, Holey ME (1987) Exploration of mechanisms regulating larval survival in Lake Michigan bloater: a recruitment analysis based on characteristics of individual larvae. Trans Am Fish Soc 116:703-718

Sharp GD (1987) Averaging the way to inadequate information in a varying world. Briefs Vol 16. American Institute of Fishery Research Biologists, Beaufort, NC (available at: http://sharpgary.org/\%23Bits1981-87.pdf), p 3-4

Shvetsov F, Hoziosky S, Rudneva A (1992) On some local properties of Baltic sprat (Sprattus sprattus balticus Schn.). Int Counc Explor Sea CM 1992/J:25:9

Sjöblom V, Parmanne R (1976) Abundance of sprat larvae in the northern Baltic in 1975. Int Counc Explor Sea CM 1976/P:13:4

Voss R, Köster FW, Dickmann M (2003) Comparing the feeding habits of co-occurring sprat (Sprattus sprattus) and cod (Gadus morhua) larvae in the Bornholm Basin, Baltic Sea. Fish Res 63:97-111

Voss R, Clemmesen C, Baumann B, Hinrichsen HH (2006) Baltic sprat larvae: coupling food availability, larval condition and survival. Mar Ecol Prog Ser 308:243-254

Wieland K, Zuzarte F (1991) Vertical distribution of cod and sprat eggs and larvae in the Bornholm Basin (Baltic Sea) 1987-1990. Int Counc Explor Sea CM 1991/J:37:12

Zar JH (1984) Biostatistical analysis, 2nd edn. Prentice-Hall, Englewood Cliffs, NJ

Submitted: August 29, 2005; Accepted: November 4, 2005 Proofs received from author(s): June 9, 2006 